\title{
Focal Scalp Hair Heterochromia in an Infant
}

$$
\text { تغاير الشعر البؤري لفروة الرأس في رضيع }
$$

$$
\text { برامود كومار }
$$

ABSTRACT: Hair heterochromia involves the presence of two different non-artificially induced colours of hair in the same individual which can be due to either iron deficiency anaemia, genetic mutations or mosaicism. We report a six-month old male infant who presented to the Department of Dermatology, Saham Hospital, Saham, Oman, in 2013 with focal scalp hair heterochromia without any detectable underlying abnormalities. The area of heterochromia was still noticeable at a one-year follow-up.

Keywords: Pigmentation Disorders; Hair Color; Hair Diseases; Mosaicism; Infant; Case Report; Oman.

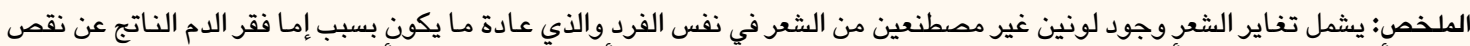

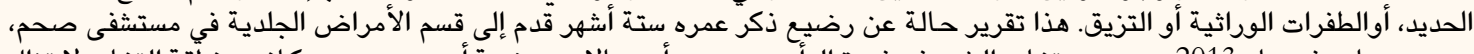

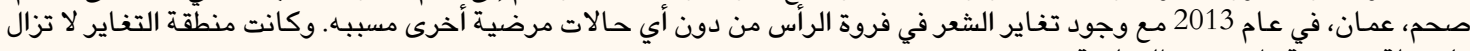

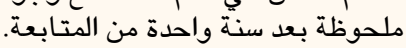

$$
\begin{aligned}
& \text { الكلمات المفتاحية: اضطرابات التصبخ؛ لون الشعر؛ أمراض الشعر؛ التزيق؛ رضيع؛ تقرير حالة؛ عمان. }
\end{aligned}
$$

$\mathrm{H}$ Air heterochromia is CHARACTERISED by the presence of hair of two naturallyoccurring different colours in an individual. Although scalp and facial hair can often be different colours in fairer-haired individuals, hair on the rest of the body tends to be much darker than the scalp hair. ${ }^{1}$ Eyelashes are usually also more darkly pigmented than scalp hair for most people. Moreover, a slight variation in the colour of individual hair shafts can sometimes be seen in a normal scalp. ${ }^{1}$ This report describes an infant with a circular patch of focal scalp hair heterochromia without any underlying abnormalities.

\section{Case Report}

A six-month-old Omani male infant presented to the Department of Dermatology, Saham Hospital, Oman, in 2013 with a patch of different coloured hair on his head. The child was active and growing at an age-appropriate rate. A local examination revealed a focal circular area of golden-yellow hair $3 \mathrm{~cm}$ in diameter on the right side of the scalp, located at the midline in the occipital area of the head [Figure 1A]. The heterochromatic hairs were consistent in colour from the root to the tip of the hair shaft. The rest of the hair on his scalp as well as the eyebrows and eyelashes were light brown. The skin under the lesion was not depigmented. No other family members had previously reported similar pigmentation disorders.
Routine investigations, including total iron binding capacity, serum ferritin and serum copper levels, did not reveal any nutritional deficiencies.

An examination of the heterochromic hair under a light microscope revealed a homogenous distribution of pigment along the hair length. No thinning was noted when compared with the darker scalp hair. A Wood's lamp examination of the skin and hair also did not reveal any abnormalities. The density of the heterochromatic hair was the same as that of the normal scalp hair and there were no loose hairs, as evidenced by a hair pull test. There was no clinical evidence of an underlying naevus or heterochromia of the hair elsewhere on the body. At a one-year follow up, the scalp hair had become dark brown, although the patch of light-coloured heterochromatic hair remained unchanged [Figure 1B].

\section{Discussion}

Eumelanin and pheomelanin combine to form most of the naturally-occurring hair, eye and skin colours during a process known as mixed melanogenesis. ${ }^{2}$ Although blond hair contains mostly eumelanin, Ito et al. concluded that the yellowish tint of blond hair is due to the high dilution of eumelanin, while pheomelanin does not play a significant role. ${ }^{2}$ While the exact mechanism which makes blond hair appear 


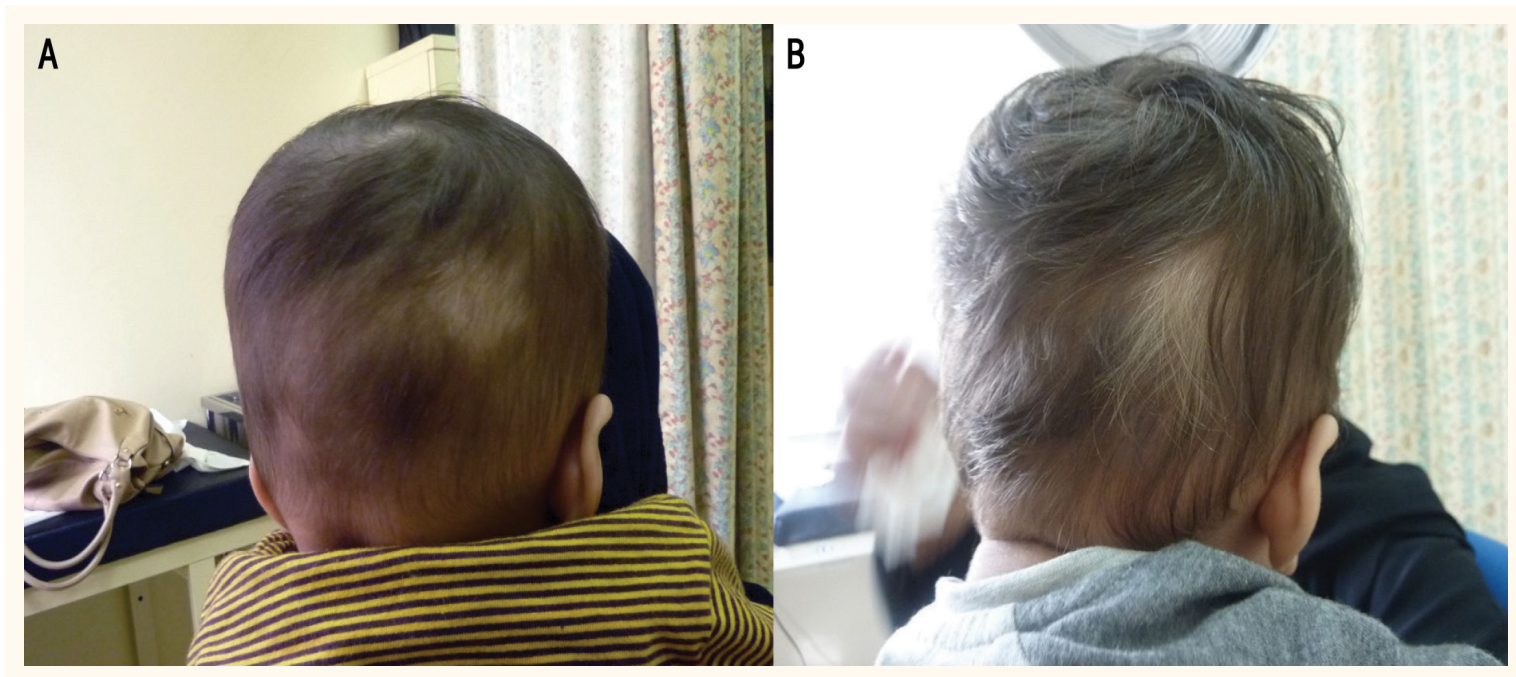

Figure 1: Focal area of heterochromic hair on the scalp of a six-month-old male infant at (A) presentation and (B) a one year follow-up.

yellowish is unknown, the researchers suggested that suppressed melanogenesis in blond hair may lead to smaller eumelanin polymers, resulting in a yellow appearance. $^{2}$

Discrete patches of lighter or darker coloured hair with a Blaschkoid distribution may occur in rare cases. ${ }^{3,4}$ Several reports of segmental hair heterochromia have been published in which demarcated variations in colour occur along a single hair shaft. ${ }^{5,6}$ This variation usually takes the form of an intermittent loss of pigmentation. Sato et al. described a 15-yearold girl with segmented heterochromia associated with iron deficiency anaemia; the patient subsequently recovered completely following treatment with an iron supplement. ${ }^{7}$ Tomita et al. reported a case of white scalp hair in an infant with Menkes disease who had low levels of eumelanin and pheomelanin; the discolouration resolved after the administration of copper histidinate. ${ }^{8}$ A solitary case of nummular headache associated with focal hair heterochromia in a child has also been reported. ${ }^{9}$

Three different types of hair heterochromia have been previously described: patchy, segmental and diffuse. ${ }^{10}$ The patient in the current case had heterochromia of one area of scalp hair and thus was diagnosed with patchy or focal heterochromia. Focal hair heterochromia, owing to its presentation in isolated areas, is an indication of mosaicism. ${ }^{11,12} \mathrm{~A}$ similar case was reported in Japan with systematic naevus depigmentosus and focal blond hair on a portion of the scalp; the eumelanin content in the hair was low although pheomelanin levels were normal. ${ }^{13}$ However, a systemic examination in the current case did not reveal evidence of the involvement of any other systems. Moreover, the patient did not have any nutritional deficiencies and the colouration of the affected hair was uniform along the whole shaft. As such, somatic mosaicism leading to the dilution of hair pigment in a focal area of the scalp was considered the most likely explanation for the heterochromia in the current case.

\section{Conclusion}

Focal hair heterochromia may be caused by iron deficiency anaemia or Menkes disease and can be associated with underlying naevus depigmentosus. This case report described a case of focal scalp hair heterochromia without any underlying abnormalities; moreover, the heterochromia was found to have persisted at a one-year follow-up. As such, somatic mosaicism was concluded to be the most likely explanation for the heterochromia.

\section{References}

1. Messenger AG, de Berker DA, Sinclair RD. Disorders of hair. In: Burns T, Breathnach S, Cox N, Griffiths C, Eds. Rook's Textbook of Dermatology, 8th ed. Oxford, UK: Wiley-Blackwell, 2010. Pp. 66.1-100. doi: 10.1002/9781444317633.ch66.

2. Ito $\mathrm{S}$, Wakamatsu K. Diversity of human hair pigmentation as studied by chemical analysis of eumelanin and pheomelanin. J Eur Acad Dermatol Venereol 2011; 25:1369-80. doi: 10.11 11/j.1468-3083.2011.04278.x.

3. Iorizzo M, Piraccini BM, Tosti A. Heterochromia of the scalp hair following Blaschko lines. Pediatr Dermatol 2007; 24:69-70. doi: 10.1111/j.1525-1470.2007.00338.x.

4. Dumitrascu CI, Hoss E, Hogeling M. Heterochromia of the hair and eyelashes with Blaschkoid dyspigmentation. Pediatr Dermatol 2016; 33:e121-2. doi: 10.1111/pde.12738.

5. Yoon KH, Kim D, Sohn S, Lee WS. Segmented heterochromia in scalp hair. J Am Acad Dermatol 2003; 49:1148-50. doi: 10.1016/S0190-9622(03)00471-7. 
6. Cho SB, Zheng Z, Kim JY, Oh SH. Segmented heterochromia in a single scalp hair. Acta Derm Venereol 2014; 94:609-10. doi: 10.2340/00015555-1790.

7. Sato S, Jitsukawa $K$, Sato $H$, Yoshino $M$, Seta S, Ito $S$, et al. Segmented heterochromia in black scalp hair associated with iron-deficiency anemia: Canities segmentata sideropaenica. Arch Dermatol 1989; 125:531-5. doi: 10.1001/arch derm.1989.01670160079015.

8. Tomita Y, Kondo Y, Ito S, Hara M, Yoshimura T, Igarashi H, et al. Menkes' disease: Report of a case and determination of eumelanin and pheomelanin in hypopigmented hair. Dermatology 1992; 185:66-8. doi: 10.1159/000247407.

9. Dabscheck G, Andrews PI. Nummular headache associated with focal hair heterochromia in a child. Cephalalgia 2010; 30:1403-5.doi: 10.1177/0333102410368439.
10. Park YJ, Sohn YB, Sohn S, Kim YC. Isolated patchy heterochromia of the scalp hair. Eur J Dermatol 2015; 25:342-3. doi: $10.1684 /$ ejd.2015.2554.

11. Restano L, Barbareschi M, Cambiaghi S, Gelmetti C, Ghislanzoni M, Caputo R. Heterochromia of the scalp hair: A result of pigmentary mosaicism? J Am Acad Dermatol 2001; 45:136-9. doi: 10.1067/mjd.2001.113688.

12. Bonamonte D, Filoni A, Vestita M, Angelini G, Foti C. Scalp hair heterochromia in a 5-year-old child: Rare somatic mosaicism? Pediatr Dermatol 2014; 31:733-4. doi: 10.1111/pde.12393.

13. Fukai K, Ishii M, Kadoya A, Hamada T, Wakamatsu K, Ito S. Nevus depigmentosus systematicus with partial yellow scalp hair due to selective suppression of eumelanogenesis. Pediatr Dermatol 1993; 10:205-8. doi: 10.1111/j.1525-1470. 1993.tb00363.x.

\title{
ACCESS TO FULL-TEXT ARTICLES
}

\author{
All articles published in SQUMJ can be found online in \\ PubMed and the full text is freely available on PubMed \\ Central and the SQUMJ content website.
}

